\title{
TOOL STEEL QRO90 SUPREME AFTER FOUR TYPES OF HEAT TREATMENT
}

\author{
1Eva MAZANCOVÁ, ²Pavel KUČERA \\ ${ }^{1}$ VŠB-Technical University of Ostrava, Faculty of Materials Science and Technology, 17. listopadu 15/2172, \\ 70833 Ostrava, Czech Republic, EU, eva.mazancova@vsb.cz \\ ${ }^{2}$ Vitkovice Cylinders a.s., Ruská 24/83, 70600 Ostrava-Vitkovice, Czech Republic, EU, \\ pavel.kucera@vitkovice.cz
}

https://doi.org/10.37904/metal.2020.3492

\begin{abstract}
Paper deals with tool steel of QRO90 Supreme type that was treated by four different heat treatments. Firstly only laser quenched, afterwards laser quenched with followed-up plasma nitridation, the third material was only nitrided by plasma and the last one was nitrided by plasma and subsequently laser quenched. Microstructures with purity and micro-hardness in different depths under surface were investigated, so that to find the optimised heat treatment leading to the most favourable mechanical properties of the studied steel with taking tribological properties into consideration. Obtained results were compared mutually including results from material after conventional quenching. Laser quenched material with followed nitridation shapes up as the most optimised heat treatment variant
\end{abstract}

Keywords: QR090 Supreme tool steel, laser quenching, plasma nitriding, microhardness, microstructure

\section{INTRODUCTION}

Tool steels of new generation should show longer life time, higher hardness that can be reached using laser quenching ( $L Q)$ and/or plasma nitriding (PN). The $L Q$ makes diffusion process in surface layers faster and the $\mathrm{PN}$ is able to make the treatment time by 2-8 hours shorter. By combination of both HT processes it is possible to increase material hardness, wear level and elastic modulus of nitrided layer [1]. Simultaneously, porosity has been decreased and hardness has been increased without thickness change. Combination of both mentioned HT has been object of research [1] and tool steel of QRO90 Supreme is one of materials belonging to the target group.

Tool steel of QRO90 Supreme is applied for stamping and mould casting. Both technologies are characterized in that the tool gives final product shape and are plenteously used for complicated products in shape without any other working. Such exact tools are expensive for production and must be made from special steel type. Steel used for hot forming must show a resistance against high temperatures and simultaneously against pressures and abrasion [2,3]. All tool steels for hot working are used in quenched and tempered state and tool steel must keep a high heat strength, plasticity, toughness, heat conductivity, creep strength, resistance against tempering and low heat expansion up to $550 / 650^{\circ} \mathrm{C}[4,5]$. For preservation of such properties up to higher temperatures effect of secondary hardness is used that can be reached by addition of carbides formed elements as $\mathrm{Cr}$, W, Mo and V [5,6] and making softening lower.

The aim of presented work is study of surface, resp. under surface layers of QRO90 Supreme tool steel after different combinations of surface laser quenching and/or plasma nitriding and finding an optimised way of surface heat treatment for mentioned steel with high mechanical parameters and finding the impact of hardness on tribological properties. 


\section{EXPERIMENTAL}

In dimension the same five samples of QRO90 Supreme tool steel (AISI H10) after different heat treatments $(\mathrm{HT})$ for microstructure analyses were labelled as it follows. The BM represents basic material without any HT, sample labelled 1 laser quenching (LQ) up to 0.7 - $0.9 \mathrm{~mm}$ depth only, while sample 2 was after laser quenching up to $0.7-0.9 \mathrm{~mm}$ depth with followed plasma nitriding up to $0.2-0.3 \mathrm{~mm}$ depth (LQ+PN). Sample 3 was nitrided by plasma up to $0.2-0.9 \mathrm{~mm}$ depth (PN) unlike sample 4 that was nitrided by plasma and subsequently laser quenched up to $0.7-0.9 \mathrm{~mm}$ depth (PN+LQ). Conditions for heat treatments were in all cases the same. All samples were metallographically grinded and polished for study of their surfaces, resp. under surface areas, including purity, microstructure with grain size, hardness HVO.2 (LECO 2000) and diffusional layers. For qualitative linear chemical analysis SEM QUANTA 450 with EDAX Octane FEG was used. For light microscopy device Olympus IX 70 was at disposal. Chemical composition of QRO90 Supreme tool steel was followed (in wt\%): $0.38 \mathrm{C}, 0.3 \mathrm{Si}, 0.75 \mathrm{Mn}, 2.6 \mathrm{Cr}, 2.25 \mathrm{Mo}$ and $0.9 \mathrm{~V}$. With exception of sample 1 (LQ) tribological tests were also carried out by means of PIN-on-DISC method. Wear coefficient W ranged from $1.9 \mathrm{~mm} / \mathrm{N} \cdot \mathrm{m}(\mathrm{BM})$ to $(2.48$ - $2.9 \mathrm{~mm} / \mathrm{N} \cdot \mathrm{m}$ - all heat treated materials with the same character of abrasion, with even ruts and acoustical effects).

Table 1 Results of micro hardness HV0.2 of investigated material BM after LQ, LQ1+PN, PN and PN+1LQ

\begin{tabular}{|c|c|c|c|c|c|c|c|c|c|c|}
\hline $\begin{array}{c}\text { Sample after heat } \\
\text { treatment /distance from } \\
\text { surface (mm) }\end{array}$ & $\mathbf{0 . 1}$ & $\mathbf{0 . 2}$ & $\mathbf{0 . 3}$ & $\mathbf{0 . 4}$ & $\mathbf{0 . 5}$ & $\mathbf{0 . 6}$ & $\mathbf{0 . 7}$ & $\mathbf{0 . 8}$ & $\mathbf{0 . 9}$ & $\mathbf{1 . 0}$ \\
\hline BM & 595 & 586 & 587 & 570 & 589 & 600 & 578 & 576 & 593 & 584 \\
\hline LQ (1) & 681 & 644 & 619 & 614 & 600 & 581 & 488 & 494 & 481 & 484 \\
\hline LQ+PN (2) & 968 & 952 & 648 & 618 & 599 & 599 & 572 & 555 & 531 & 561 \\
\hline PN (3) & 880 & 723 & 694 & 581 & 590 & 572 & 581 & 563 & 580 & 547 \\
\hline PN+LQ (4) & 933 & 659 & 560 & 544 & 547 & 539 & 535 & 523 & 531 & 524 \\
\hline
\end{tabular}
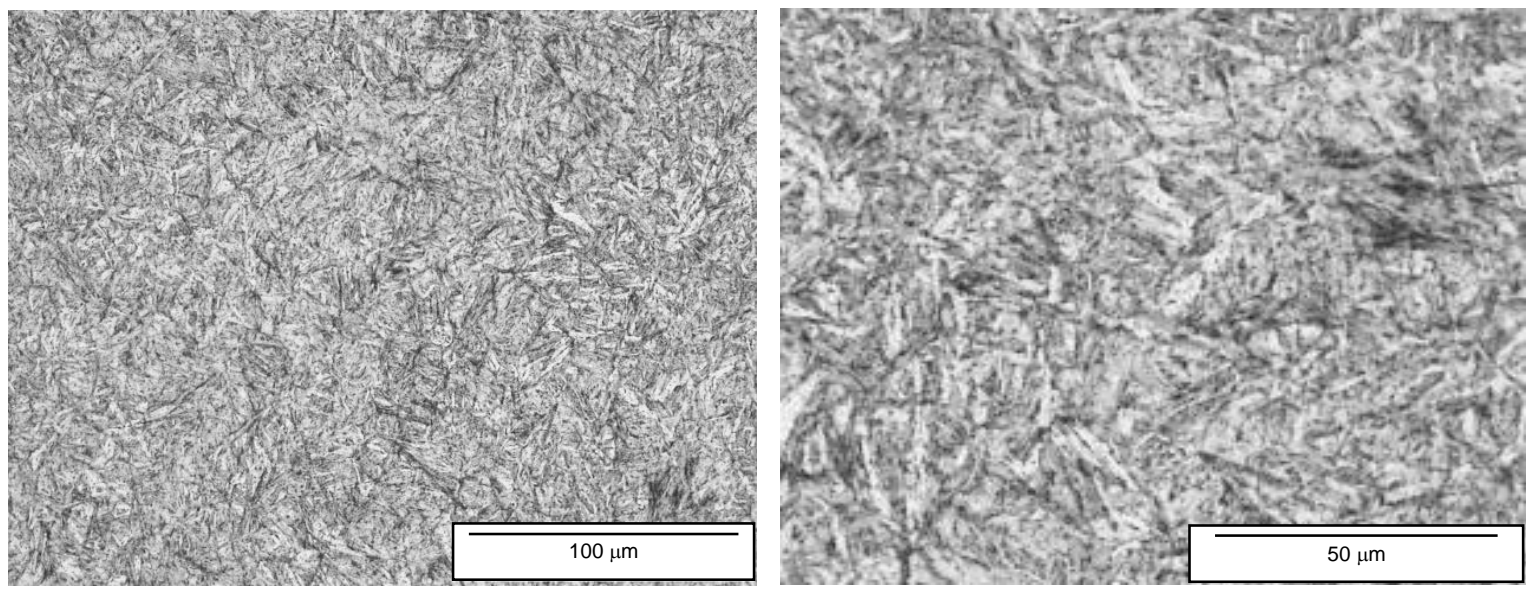

Figure 1 Microstructure of basic material $(B M)$ - two magnifications

\section{RESULTS AND THEIR ANALYSIS}

In BM globular oxides of D1 and DS0.5 types were found. Hardness ranged from 570 to $600 \mathrm{HV} 0.2$, on average it was $586 \mathrm{HV0.2}$ as it from Table 1 can be seen. According ARA-diagrams [2] microstructure should be martensitic-bainitic one, however only martensitic microstructure with fine martensitic needles was detected, as it Figure 1 demonstrates and results from work [7] support. Average austenite grain size corresponded to $7 \pm 4 \mu \mathrm{m}$, including also the highest sporadic occurrence of $15 \mu \mathrm{m}$ grains. 
Microstructure of LQ material shows Figure 2."In laser zone ultrafine microstructure formed. White part of LQ layer is named molten zone and under that one heat affected zone (HEZ) can be detected. The LQ zone shows high homogeneity, abrasion and corrosion resistance. Hardness of that part showed 681 HV0.2. In depth of approx. $710 \mu \mathrm{m}$ (Figure 2a) the HEZ was observed with important fall of HV, under level of BM, as it from above mentioned BM results and Table 1 follows. Molten zone turned to martensitic heat affected zone. In molten zone extremely ultrafine martensitic microstructure with ultrafine carbides (of Mo and $\mathrm{V}$ type) was seen. On the surface approx. $10 \pm 1 \mu \mathrm{m}$ thick Fe oxide layer formed by $\mathrm{Fe}_{1-\mathrm{x}} \mathrm{O}, \mathrm{Fe}_{3} \mathrm{O}_{4}$ and $\mathrm{Fe}_{2} \mathrm{O}_{3}$ as an effect of high temperature and/or contamination of environment was observed [8].
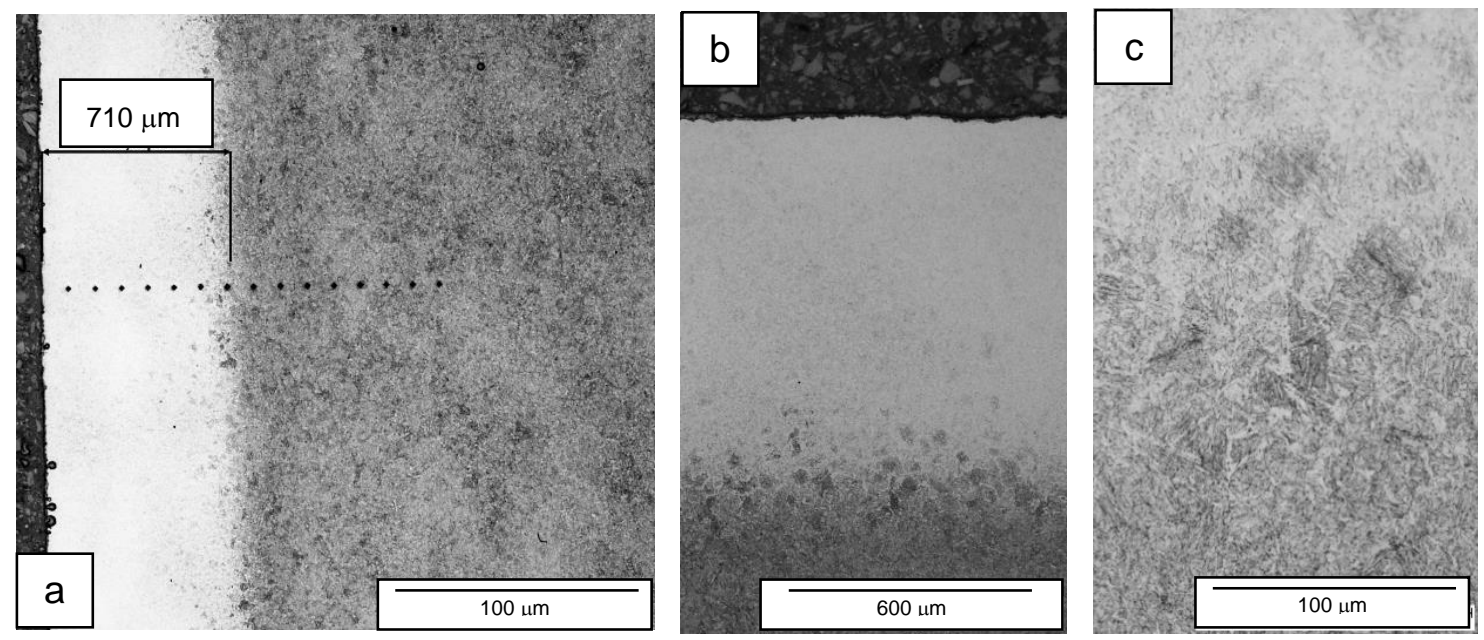

Figure 2 Microstructure of LQ material a) formed layers under surface, b) molten zone in detail, c) transition of molten zone into the HAZ and the BM
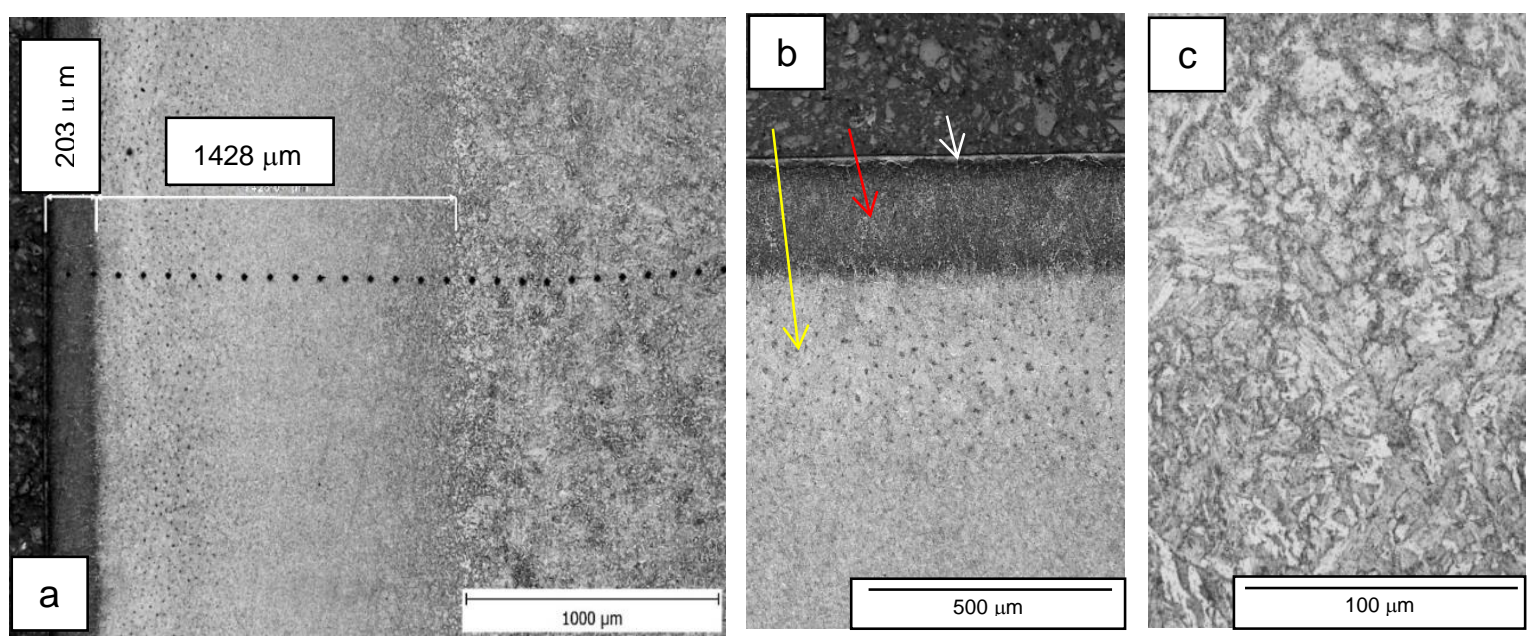

Figure 3 Microstructure of LQ+PN material a) formed layers under surface - $203 \mu \mathrm{m}$ represents mixed layer, $1428 \mu \mathrm{m}$ layer includes all deeper detected zones b) white layer (white arrow), mixed layer (red arrow), diffusion zone (yellow arrow), martensite and HAZ bellow diffusion layer $\mathrm{c}$ ) transition to the basic material from undersurface formed zones

Figure 3a shows course of layers in LQ+PN material being in agreement with results of work [9]. Thickness of mixed layer under surface was approx. $203 \mu \mathrm{m}$ subsequent diffusion nitride layer turned to laser quenched one and this layer to the HAZ being totally $1428 \mu \mathrm{m}$ in thickness as it Figure 3a demonstrates. Next layer represents unaffected material as it from Figure 3a follows. Maximal hardness was found in depth of $100 \mu \mathrm{m}$ 
(see Table 1), in which also maximal volume fraction of $N$ was detected (5.8 wt\%), together with $\varepsilon$ and $\gamma$ phases as it linear chemical analysis revealed. Up to $200 \mu \mathrm{m}$ distance away surface fall of HV0.2 was detected, where $\mathrm{N}$ level was stabilized on $3 \pm 1 \mathrm{wt} \%$. In distance of $300 \mu \mathrm{m}$ hardness was stabilized on the lowest level as well as $\mathrm{N}$ portion (1.5-2 wt\%).

Under mixed layer a net of carbides and/or carbide nitrides can be observed. Nitrided layer $(15 \pm 1 \mu \mathrm{m})$ "is formed by $\mathrm{Fe}$ and $\mathrm{N}$ and this layer can be seen as a white one on the polished section and can be influenced by composition of nitridation atmosphere. In case of addition of $C$ to mentioned atmosphere intermetalic phase $\varepsilon-\mathrm{Fe}_{2-3} \mathrm{~N}$ is formed. This layer corresponds to range from 8 to $30 \mu \mathrm{m}$ in thicknes. In given case mentioned layer was $15 \mu \mathrm{m}$. During standard gas nitridation more phase layers of $\varepsilon_{-}-\mathrm{Fe}_{2-3} \mathrm{~N}$ and $\gamma-\mathrm{Fe}_{4} \mathrm{~N}$ are formed. [10, 11]. Dark zone under above described layer represents diffusion part, when $N$ atoms occupy the bcc lattice interstitial positionsins [10]. Diffusion layer is noticeably thicker (see yellow arrow in Figure $\mathbf{3 b}$ ). The grain size of the HAZ oscillated about $18 \mu \mathrm{m}$.
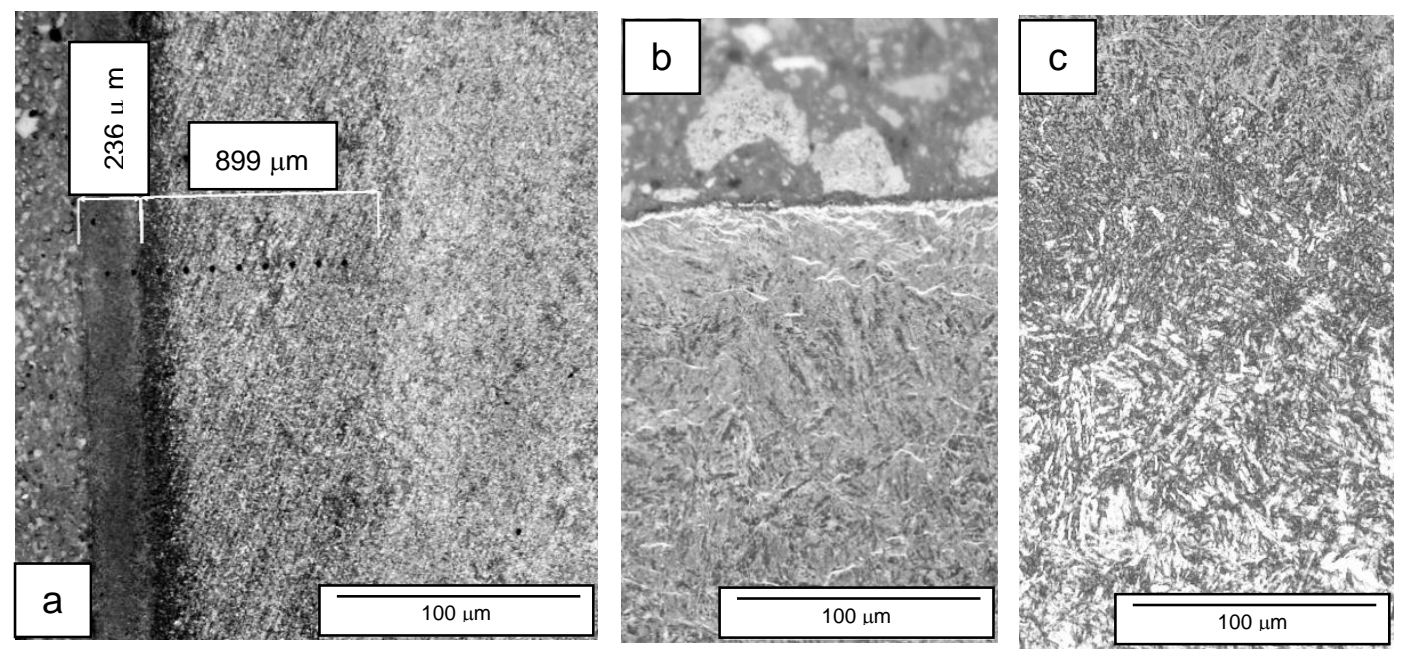

Figure 4 Microstructure of PN material a) formed layers under surface, b) transition white layer-diffusion zone in detail, c) transition from nitrided layer to BM

Figure 4 shows material microstructure after PN. In $100 \mu \mathrm{m}$ depth maximal hardness (880 HV0.2) was detected. This one was increasing, up to $300 \mu \mathrm{m}$ faster and then was practically stagnated, lightly above the basic material level, as it from Table follows. Investigated steel falls into class of medium or high alloyed materials being able to reach hard layers, however thickness of diffusion zone is never higher than 0.5/0.6 $\mathrm{mm}$. Steels with Cr-Mo-V addition have achieved higher lifetime (max. $250 \%$ ) generally [11]. The PN sample showed the highest portion of $\mathrm{N}$ on the surface and directly under surface (over $9 \mathrm{wt} \%$ ). Each $0.5 \mathrm{wt} \% \mathrm{~N}$ decrease represented hardness fall by $50 \mathrm{HV} 0.2$ approximately. In distance of 30-35 $\mu \mathrm{m}$ only $3 \mathrm{wt} \%$ of N was revealed, while in distance of $350 \mu \mathrm{m}$ away surface it was $1.5 \mathrm{wt} \%$. That level was practically stable up to 1 $\mathrm{mm}$ depth. Diffusion layer corresponded to $236 \pm 20 \mu \mathrm{m}$ (Figure 4a), white layer to 5-9 $\mu \mathrm{m}$ (Figure 4b). Average microstructure grain size of diffusion layer was $8 \mu \mathrm{m}$, while transition to basic material revealed 12 $\mu \mathrm{m}$ grain size. Generally, properties of nitrided surface depend on applied temperature, because with decreasing temperature also hardness is going down, however not on nitriding time, because that takes 15 hours approximately. Optimized tribological properties are the reason [11].

Figure 5 represents microstructure of $P N+L Q$ sample. Micro-hardness of that sample went down significantly. Higher micro-hardness was in depth of $100 \mu \mathrm{m}$. After transition from diffusion zone to LQ one micro-hardness was stabilized on the half level and that corresponded to the BM. In this heat treatment variant nitrogen concentration was higher than in case of LQ+PN sample. In depth of $100 \mu \mathrm{m}$ micro-hardness was 933 HV0.2 
afterwards it was $659 \mathrm{HV} 0.2$ in depth of $200 \mu \mathrm{m}$. With further nitrogen fall micro-hardness was evenly going down up to $560 / 540 \mathrm{HV} 0.2$ in depth of $300 / 400 \mu \mathrm{m}$. White layer length corresponded to $8 \pm 2 \mu \mathrm{m}$ (Figure $5 \mathrm{~b}$ ), while diffusion zone was $316 \mu \mathrm{m}$ in thickness (Figure 5a). Micro-hardness of this sample was lower as it was already mentioned above. The reason has been nitrides formation after nitriding and their follow-up dissolution after LQ procedure and/or a change their interatomic distances after the LQ. The white layer has been also thinner (1.9 times) than in case of above mentioned sample LQ+PN. The grain size of diffusion zone microstructure corresponded to $6 \mu \mathrm{m}$, unlike the layer of LQ (HAZ) microstructure being $12 \mu \mathrm{m}$ approximately.
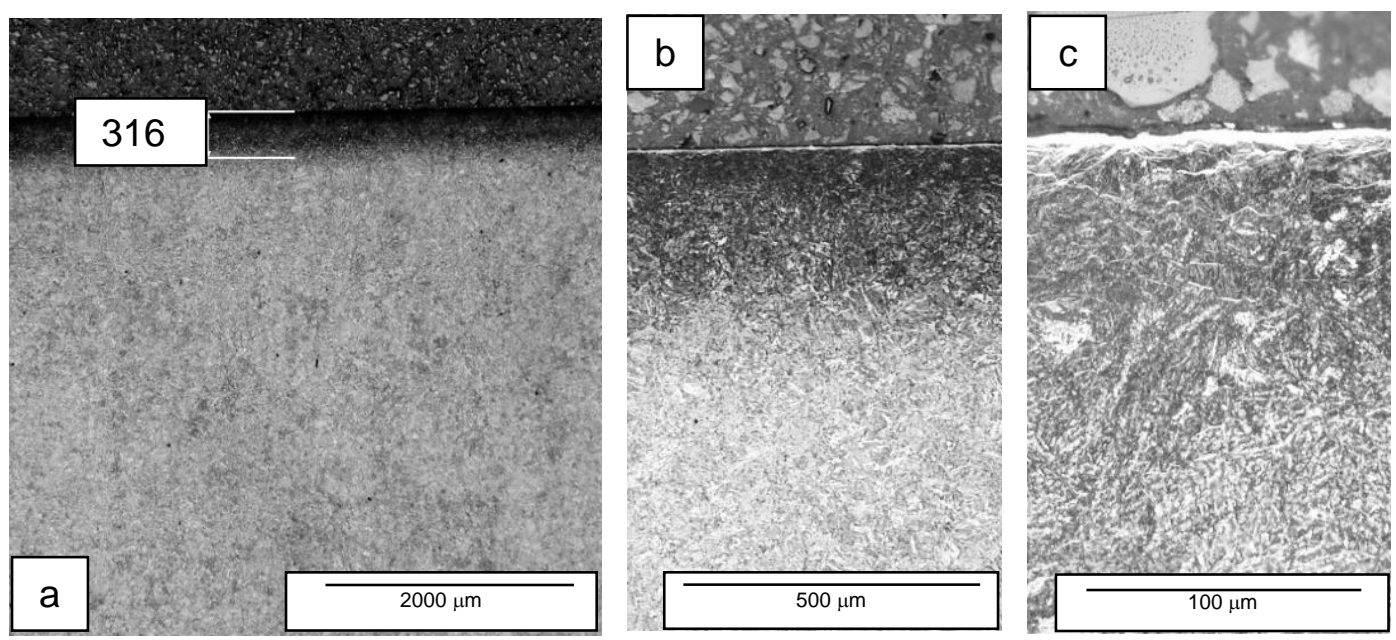

Figure 5 Microstructure of $P N+L Q$ material a) formed layers under surface, b) transition white layer-diffusion zone, LQ, c) white layer and diffusion zone in greater detail

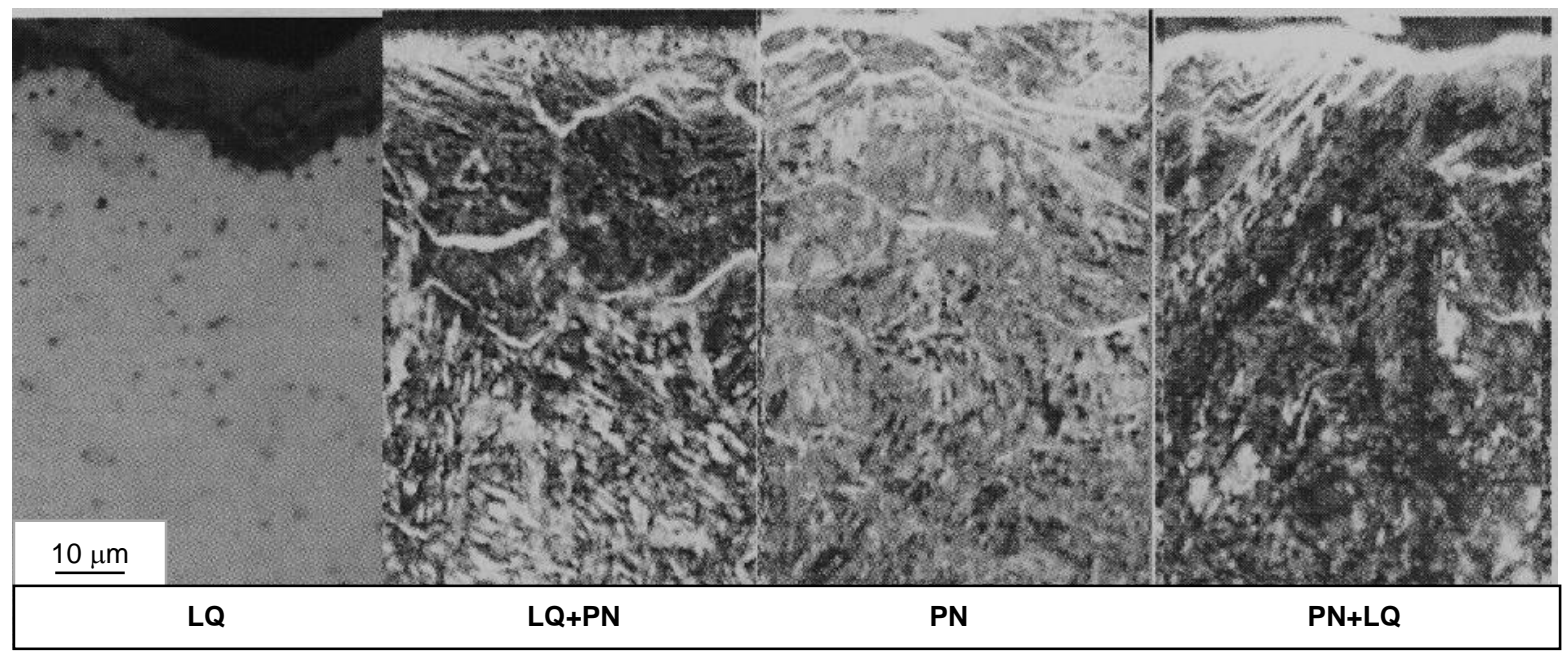

Figure 6 Comparison of formed microstructures after 4 heat treatment variants on the surfaces, resp. directly under surfaces (magnification is the same in all cases)

From the results follows, the most favourable variant of heat treatment could be taken LQ+PN material showing high hardness after $L Q$ treatment by means of the surface/under surface white layer of extremely fine martensite of $22 \mu \mathrm{m}$ in local thickness (Figure 6) being further hardened after the PN treatment at temperature of $480-500{ }^{\circ} \mathrm{C}$ during 15 hours leading to a change of primary microstructure and to nitrides, resp. carbonitrides formation of fine size as it from Figure 6 follows. The primary under surface hardness (681 HV0.2) after LQ process was increased by $42 \%(968 \mathrm{HV} 0.2)$ - see Table 1. The second best results the PN+ $L Q$ variant revealed on the surface, resp. under surface up to $100 \mu \mathrm{m}$ depth. In given case the primary micro- 
hardness of $880 \mathrm{HV} 0.2$ was changed slightly on $933 \mathrm{HV} 0.2$ (see Table 1) representing $6 \%$ growth only, however in depth of $300 \mu \mathrm{m}$ fall of micro-hardness (560 HV0.2) was found already. This week effect of double heat treatment is not economical. It is necessary to state, all variants of heat treatments showed practically the same level of tribological results. In case of $L Q+P N$ wear coefficient $W=2.62 \mathrm{~mm} / \mathrm{N} \cdot \mathrm{m}$, while the $P N+L Q$ variant revealed lightly better result $\left(\mathrm{W}=2.48 \mathrm{~mm}^{3} / \mathrm{N} \cdot \mathrm{m}\right)$.

\section{CONCLUSION}

Beside basic treatment representing conventional quenching four heat treatment variants were applied on surface and under surface of tool steel of QRO90 Supreme including laser quenching (LQ), further LQ with plasma nitriding ( $L Q+P N)$, plasma nitriding $(P N)$ and $P N+L Q$. Results were compared mutually. The lowest surface resp. under surface micro-hardness was generally detected in basic material (600 HV0.2).

The highest micro-hardness was found on the surface resp. directly under surface in case of LQ+PN variant. The second highest micro-hardness on the surface resp. directly under surface corresponded to the $P N+L Q$ variant, however in depth of $300 \mu \mathrm{m}$ approx. $40 \%$ fall of micro-hardness was already revealed what can be elucidated by dissolution of primary formed nitrides after laser quenching in more slowly cooled region. The other in order was PN material, while the LQ one showed the lowest micro-hardness on the surface (681 HV0.2). From point of tribological tests the best was basic material (wear coefficient $W=1.9 \mathrm{~mm}^{3} / \mathrm{N} \cdot \mathrm{m}$ ), while the other treated materials showed practically comparable level of $\mathrm{W}=2.48-2.9 \mathrm{~mm} / \mathrm{N} \cdot \mathrm{m}$ ).

\section{ACKNOWLEDGEMENTS}

\section{This paper was created in cooperation with company of VÍTKOVICE CYLINDERS Inc. and at the FMT within the project No. SP2020/39 - Specific research in metallurgical, material and procedural engineering.}

\section{REFERENCES}

[1] FADHIL, I.A., AKIMOV, O., KOSTYK, K. Development of a combined technology for hardening the surface layer of steel 38Cr2MoAl. Eastern-European Journal of Enterprise Technologies. 2017, vol. 86, no. 2, pp. 56-62.

[2] TRICKERI KNAPPEN, KARLSTAD. Uddeholm QRO 90 Supreme [online]. [viewed 2019-12-02]. Available from: https://www.uddeholm.com/files/PB gro 90 supreme english.pdf.

[3] UDDEHOLM LIBRARY. Uddeholm Tool Steels for Die Casting [online]. [viewed 2019-11-16]. Available from: https://www,uddeholm.com/files/AB_die_casting_eng.pdf.

[4] SURPI DOMENICO. GRUPPO LUCEFIN. Mould and Tool Steels [online]. [viewed 2019-11-19]. Available from: http://www.lucefin.com/wpcontent/files $\mathrm{mf} / \mathrm{mouldandtoolsteels.pdf}$.

[5] KARLSTAD UNIVERSITY STUDIES. Chromium Martensitic Hot-work Tool Steel: Damage, Performance and Microstructure [online]. [viewed 2019-10-19]. Available from: https.//www.divaportal.org/smash/get/diva2:24899/FULLTEXT01.pdf.

[6] MATERIALS SUMMARY [online]. [viewed 2019-11-16]. Available from: http://uddeholm.cz/czech/files/UTPrehled materialu.pdf.

[7] KARLSTAD UNIVERSITY LIBRARY Evaluation of the Cyclic Behaviour during High Temperature Fatigue of Hot Work Tool Steels [online]. [cit. 2018-04-30]. Available from: https://www5.kau.se/sites/default/files/Dokument/subpage/2010/02/51 721736 pdf 22871.pdf

[8] LANDOLT, D. Corrosion and Surface Chemistry of Metals. Lausanne: EPFL Press, 2007.

[9] PANT, M., BLECK, W. Continuous Impact Wear Resistance of Duplex Surface-modified Hot Work Tool Steel H10 [online]. [viewed 2019-12-02]. Available from: http://linkinghub.elsevier.com/retrieve/pii/S004316480500089X.

[10] BIROL, Y. Analysis of wear of a gas nitrided $\mathrm{H} 13$ tool steel die in aluminium extrusion. Engineering Failure Analysis. 2012, vol. 26, pp. 203-210. 